RESEARCH PAPER RP1404

Part of Journal of Research of the National Bureau of Standards, Volume 27, July 1941

\title{
PHOTOCHEMICAL REACTIONS IN SILK
}

\author{
By Henry A. Rutherford and Milton Harris ${ }^{1}$
}

\section{ABSTRACT}

The stability of silk to light appears to be in part influenced by the cations in the silk. The removal of cationic substances from silk by two independent methods results in practically identical decreases in the stability of the fibers to light; the introduction of cations by treatment with basic compounds appreciably increases the stability.

Methylation of the earboxylic acid groups in silk by treatment with diazomethane does not appreciably change the photochemical behavior of the fiber, whereas methylation of only a small percentage of the hydroxyl groups of the tyrosine results in a marked increase in photochemical stability. The results suggest that alteration of the tyrosine hydroxyl groups by reaction with various reagents is responsible for at least part of these stabilizing effects.

\section{CONTENTS}

I. Introduction

II. Experimental procedure.

1. Materials

2. Methods.

III. Resuits and discussion

1. Effect of the removal of cations on the rate of deterioration . . $\quad 83$

2 .Effect of pretreatment with different cationic substances..... 84

3. Effect of methylation

4. Effect of irradiation on the tyrosine content of silk

IV. References

5. Practical significance... 87

\section{INTRODUCTION}

The results of numerous investigations have indicated that silk is probably more readily deteriorated by light than any other natural textile fiber. While the mechanism of the decomposition is not clear, it appears that the rate of decomposition may be considerably altered by pretreatment of the fiber with various chemical reagents. For example, Harris and Jessup $[1,2]^{2}$ found that silk treated with dilute solutions of sodium hydroxide is more stable towards the action of light than untreated silk, whereas the stability of silk treated with dilute solutions of sulfuric acid is greatly decreased. These findings were later substantiated by investigations by Hall [3]. Bonicatti [4], on the other hand, claimed that pretreatment with alkalies has no protective effect, but he did observe the photochemical decomposition to be greatly accelerated by treatment of the fiber with dilute solutions of mineral acids. More recently, Weilenmann [5] showed that some

\footnotetext{
${ }_{1}^{1}$ Research Associates at the National Bureau of Standards, representing the Textile Foundation.
}

2 Figures in brackets indicate the literature references at the end of this paper. 
aliphatic and aromatic amines exhibit a protective action, whereas compounds such as aliphatic amides and amino acids are not effective.

The efficacy of the basic compounds in inhibiting decomposition is of considerable interest, especially since it has recently been found by Gleysteen and Harris [6] that most of the base taken up by silk is bound by the hydroxyl groups of the amino acid tyrosine. It is now shown that the photochemical behavior of silk is associated with the behavior of the tyrosine and that alteration of the tyrosine hydroxyl groups by reaction with various reagents is responsible for at least part of the stabilizing effects noted in the past.

\section{EXPERIMENTAL PROCEDURE}

\section{MATERIALS}

The silk used in this work was a plain-woven cloth, commercially degummed, having 94 threads per inch. The cloth was first extracted with cold alcohol and with ether, and then washed in cold distilled water to remove the organic solvents. This silk is hereafter referred to as degummed silk.

The removal of cations from the silk was accomplished either by electrodialysis or by treatment with acid below $\mathrm{pH} 2.5$. This material is hereafter referred to as electrodialyzed silk or acid-treated silk, according to the process by which it was prepared. Purification by electrodialysis has the advantage of eliminating possible secondary reactions which may be produced by treatment of the fibers with acidic solutions.

Methylated samples were prepared using diazomethane according to the procedure recently described by Rutherford, Patterson, and Harris [7]. The acidic groups of degummed and of electrodialyzed silk have different rates of reaction with diazomethane, and it was possible to methylate an approximate, predetermined fraction of the carboxylic acid and tyrosine hydroxyl groups. The extent of methylation of each of these groups was directly determined by the procedure previously described [7]. The decrease in tyrosine content is a measure of the hydroxyl groups methylated. The difference between the total methoxyl content and the methoxyl content accounted for by the decrease in tyrosine content is a measure of the carboxyl groups esterified. Samples ${ }^{3}$ I and II were treated for $1 / 4$ and for $1 \frac{1}{2}$ hours, respectively, in an ethereal solution of diazomethane but were not electrodialyzed or wet out with alcohol before the treatment; sample III was first soaked in 75-percent alcohol and then treated for $1 / 4$ hour with diazomethane. All of these samples were then electrodialyzed to remove cationic substances. Samples IV and V were electrodialyzed, wet with alcohol, and then treated for $1 / 4$ and for 16 hours, respectively, with diazomethane. With the exception of sample $V$, which lost about 15 percent in strength, the methylation process had little effect on the strength of the fabric

\section{METHODS}

The general procedure used in the preparation of the samples for irradiation was as follows: Pieces of the cloth were soaked for 30 minutes in a solution of a given reagent, the ratio of silk to solution

${ }^{3}$ See table 3, p. 86. 
being 1 to 100 . The greater part of the solution was removed by centrifuging, the cloth being suspended on a wire rack in a centrifuge tube so that practically complete separation of the sample and solution was obtained. When the same piece of cloth was given one or more additional treatments, this same procedure was followed for each treatment. The silk cloth was finally air-dried and then cut into warpwise strips $1 \frac{1}{4}$ inches wide, which were then raveled down to 94 warp threads suitable for the breaking-strength test. The samples were then exposed to the light for 20 hours. To determine the effect of light alone, a second group of samples, treated and prepared in the same way, was kept for 20 hours in the dark under conditions of temperature and humidity approximating those encountered during the light exposure.

The decrease in breaking strength of the cloth was used as a measure of the deterioration of the silk. The tensile strengths were determined on a pendulum-type machine, the samples being conditioned and tested in a room maintained at a temperature of $21^{\circ} \mathrm{C}$ and a relative humidity of 65 percent.

The source of light was the Eveready accelerated testing unit, type C3A, equipped with Eveready Sunshine carbons and Corex D ultraviolet-transmitting glass. The exposures were made for 20 hours at a temperature of $55^{\circ}$ to $60^{\circ} \mathrm{C} .^{4}$

The cationic contents of the various samples were determined quantitatively by the electrodialytic method of Sookne, Fugitt, and Steinhardt [8]. Tyrosine was determined by Lugg's method after an alkaline hydrolysis [9], and methoxyl content by the method of Vieböck and Brecker [10].

\section{RESULTS AND DISCUSSION}

\section{EFFECT OF REMOVAL OF CATIONS ON THE RATE OF DETERIORATION}

It was observed in preliminary experiments that pretreatment of the silk with practically any basic compound has the effect of reducing the rate of deterioration. This suggested the possibility that the increased stability produced by these substances might result from combination of cations with the acidic groups of the fibers, which are of two types - namely, carboxylic acid and tyrosine hydroxyl groupsand conversely, that the decreased stability observed upon treatment with dilute mineral acids might be due in part to removal of cationic substances from these groups. On the basis of these considerations, it appeared advisable to study the behavior of silk freed from these substances by electrodialysis and by treatment with acid.

The results are shown in table 1. Electrodialysis of the silk resulted in lowering the cation content from 0.13 to 0.01 milliequivalent per gram and at the same time appreciably decreased the stability of the silk to light. Similar results were obtained when the samples were pretreated with solutions of hydrochloric, sulfuric, or acetic acids at $\mathrm{pH} 2.4 .^{5}$ Thorough washing of the acid-treated samples with distilled water prior to exposure did not alter the stability to light, which indicates that the decrease in stability results from removal of cations

4 This was measured by a mercury thermometer, the bulb of which was covered by a piece of the silk, and placed the same distance from the light as the samples.

$\checkmark$ The choice of this pH was based on the titration studies of Gleysteen and Harris [6] in which it was shown that removal of cations from silk becomes appreciable below about $\mathrm{pH} 3$. 
and is not caused by the presence of free acid in the exposed samples. It was found that none of the silk samples kept in the dark exhibited any deterioration, showing that the deterioration of the irradiated silk was not thermal, but photochemical.

TABLE 1.-Effect of electrodialysis and of treatment with dilute acids on the deterioration of silk cloth

\begin{tabular}{|c|c|c|c|}
\hline Sample & Treatment & $\begin{array}{c}\text { Cation con- } \\
\text { tent }\end{array}$ & $\begin{array}{c}\text { Loss in } \\
\text { breaking } \\
\text { strength } \\
\text { on exposure } \\
\text { to light }\end{array}$ \\
\hline Degunmed & None & $M$ eqlom & $\% \quad 32$ \\
\hline Electrodialyzed. & 1vondo & .01 & 41 \\
\hline Degummed...... & $\mathrm{H}_{2} \mathrm{SO}_{4}(\mathrm{pH} 2.4)$ & .004 & 41 \\
\hline Do ....... & $\mathrm{H}_{2} \mathrm{SO}_{4}$, followed by water wash. & .005 & \\
\hline Do.......... & $\mathrm{HCl}(\mathrm{pH} 2.4)$ & .002 & 43 \\
\hline Do & $\mathrm{HCl}$, followed by water wash.. & .002 & 43 \\
\hline Do...... & $\mathrm{CH}_{3} \mathrm{COOH}(\mathrm{pH} 2.4)$ & .004 & \\
\hline Do........ & $\mathrm{CH}_{3} \mathrm{COOH}$. followed by water wash & .005 & 41 \\
\hline Electrodialyzed................... & $\mathrm{H}_{2} \mathrm{SO}_{4}(\mathrm{pH} 2.4)$ & .004 & 43 \\
\hline
\end{tabular}

\section{EFFECT OF PRETREATMENT WITH DIFFERENT CATIONIC} SUBSTANCES

During processing, such as dyeing, silk is frequently treated with acidic solutions, which, as seen from the foregoing experiments, reduces the cation content and increases the susceptibility of the fiber to damage by light. The question whether stability of acid-treated silk can be increased by replacement of cations thus becomes of importance.

Preliminary experiments showed that basic inorganic substances, such as sodium hydroxide or sodium carbonate, are efiective for increasing the stability of the silk, but they impart a harsh, undesirable feel to the cloth. It was observed, however, that basic organic compounds do not produce such undesirable effects, and accordingly, a few of these types of compounds were studied. The effect of pretreatment of samples of degummed and electrodialyzed or acid-treated silk with $0.01 M$ solutions of several cationic compounds is shown in table 2. The data show that the deleterious effect, on light exposure, produced by acidic treatments can be reversed by treatments of the silk with suitable reagents. It is seen that the stability of the silk to light increases with increase in $\mathrm{pH}$ of the solutions used for treatment of the silk. This is to be expected, since as shown by the titration curve of silk [6], the binding of cations also increases with increasing $\mathrm{pH}$. In addition to $\mathrm{pH}$, the chemical nature of the cationic substance may also influence the rate of the photochemical decomposition, but sufficient data are not available to enlarge upon this point.

In general, the inhibiting action of a given compound was independent of the history of a given sample; thus, degummed, acidtreated, or electrodialyzed silks all exhibited the same stability after treatment with a given reagent. 
TABLE 2.-Effect of different cationic substances on the deterioration of silk

\begin{tabular}{|c|c|c|c|}
\hline Sample & Treatment * & $\begin{array}{c}\text { prr of solu- } \\
\text { tion }\end{array}$ & $\begin{array}{c}\text { Loss in } \\
\text { breaking } \\
\text { strength } \\
\text { on expo- } \\
\text { sure to } \\
\text { light }\end{array}$ \\
\hline \multicolumn{4}{|l|}{ Degummed. } \\
\hline $\begin{array}{l}\text { Acid-treated. } \\
\text { Electrodialyz }\end{array}$ & & & 41 \\
\hline $\begin{array}{l}\text { Electrodialyze } \\
\text { Degummed }\end{array}$ & Dodecyitrimethylammonium bromide (tec & & \\
\hline Acid-treated. & do & 6.0 & 33 \\
\hline Degummed.. & .....do. & 9.8 & 24 \\
\hline Acid-treated. & & 9.8 & \\
\hline Degummed. & Triethanolamine.... & 10.4 & \\
\hline Acid-tre & _._. do . . . . & 10.4 & 23 \\
\hline Electrodi & do & 10.4 & \\
\hline Degummed.... & Trimethylbenzylammonium hydroxide ... & 11.5 & 21 \\
\hline Acid-t & (1.2. & 11.5 & 19 \\
\hline Electrodialyzed. & (3) & 11.5 & 19 \\
\hline Degummed -. & Dimethyldibenzylammonium hydroxide....... & 11.5 & 21 \\
\hline Acid-tre & do & 11.5 & 21 \\
\hline Electrodialyzed. & - do do & 11.5 & 21 \\
\hline
\end{tabular}

a The concentration of the solutions was $0.01 M$. Treatment with more concentrated solutions gave no additional protection.

It was noted that the use of a cationic substance in the form of the salt, such as dodecyltremethylammonium bromide (tech.), had no effect on the degummed silk, although it did raise the stability of the acid-treated sample to that of the degummed sample. Addition of enough dilute sodium hydroxide to raise the $\mathrm{pH}$ of the salt solution to 9.8 produced a significant increase in the stability of both, although an equivalent amount of sodium hydroxide alone had no measurable effect on the silk. The reason for this is found in the titration studies of silk [6], in which it was shown that, at a given $\mathrm{pH}$, silk combines with considerably more base in the presence of salts than in their absence.

When the samples which had been treated with the reagents listed in table 2 were washed thoroughly with distilled water, most of the inhibiting effects of the reagents were eliminated. The stabilities were lowered to about that of the original degummed silk, but they were still higher than those of the electrodialyzed or acid-treated samples. The $\mathrm{pH}$ of the water used for washing the samples was about 6.5 , and accordingly, the silk would have still retained appreciable amounts of cations [6], which would account for these differences. It may be that Bonicatti's [4] failure to observe the stabilizing effect of cations resulted. from his use of degummed silk which might have contained appreciable amounts of cation. This appears likely, since he found a marked decrease in the stability of his silk when he pretreated it with acid.

\section{EFFECT OF METHYLATION}

It is shown in the previous sections that the removal of cationic substances from silk by two independent methods results in practically identical decreases in stability to light, but that the stability can be restored by treatment with basic compounds. The question therefore arises whether the decreased stability obtained after electrodialysis or acid treatment is caused by the removal of cations from the carboxylic acid or the tyrosine hydroxyl groups, or from both. 
It is not possible to ascertain by a simple experiment whether the cations are combined with carboxyl groups, tyrosine hydroxyl groups, or both. However, it is possible to inactivate known amounts of either type of group with diazomethane [7]. The results of such a procedure, applied to silk containing 0.002 milliequivalent, or less, of eation per gram, are shown in table 3 . It was found that methylation of 5 percent of the hydroxyl groups produces a significant increase in the stability of the silk. Samples II, III, and IV were approximately equal with regard to the methylation of the hydroxyl groups and equal with regard to their stabilities to light, although they differed greatly with respect to the extent of methylation of their carboxyl groups. This shows that the methylation of the latter has no effect on the stability of the silk. However, a further increase in the methylation of the hydroxyl groups, from 17 to 87 percent of the total, produced still greater stability. The stabilities attained are comparable to the stabilities of those samples which were treated in alkaline solutions at $\mathrm{pH} 10.4$ or above (table 2). Some additional evidence suggesting a confirmation of this explanation for an increase in the stability of silk on treatment in basic solutions was obtained in the following way. Portions of samples IV and V were treated with triethanolamine and trimethylbenzylammonium hydroxide, and the treated samples were then irradiated for 20 hours. As shown in table 4, treatment of sample $\mathrm{V}$ had little additional effect on stability. This was to be expected since most of the hydroxyl groups had already been methylated. On the other hand, the stability of IV after similar treatments was appreciably increased. In this sample, however, a large number of hydroxyl groups were still available for combination with the cations.

The increase in stability of silk, obtained by replacing the hydrogen of the hydroxyl group of tyrosine by methyl groups or by various cations, may result from a change in the absorption spectrum of the silk. The absorption spectra of some simple aromatic hydroxyaldehydes and hydroxy-ketones are changed by similar treatments [11].

TABLE 3.-Effect of selectively methylating carboxyl and tyrosine hydrowyl groups with diazomethane on the deterioration of silk

\begin{tabular}{|c|c|c|c|}
\hline Sample & Carboxyl & $\begin{array}{l}\text { Tyrosine } \\
\text { hydroxyl }\end{array}$ & $\begin{array}{l}\text { Loss in } \\
\text { breaking } \\
\text { strength on } \\
\text { exposure } \\
\text { to light }\end{array}$ \\
\hline $\begin{array}{l}\text { Electrodialyzed } \\
\text { I } \\
\text { II } \\
\text { II- } \\
\text { IV } \\
\text { V }\end{array}$ & $\begin{array}{c}\text { \% of total } \\
0.0 \\
0 \\
15 \\
31 \\
67 \\
100\end{array}$ & $\begin{array}{c}\text { \% of total } \\
0.0 \\
5 \\
16 \\
15 \\
17 \\
87\end{array}$ & $\begin{array}{r}\% \\
41 \\
35 \\
31 \\
31 \\
32 \\
23\end{array}$ \\
\hline
\end{tabular}


TABLE 4.-Effect of cationic substances on the deterioration of samples of silk methylated to different extents



\section{EFFECT OF THE IRRADIATION ON THE TYROSINE CONTENT} OF SILK

The deterioration of silk fibers by photochemical reactions probably results from a photochemical fragmentation of the polypeptide chains of the protein [3]. Some of the tyrosine may be destroyed [12, 13] and peptide linkages adjacent to the tyrosine cleaved [14]. Destruction of some of the tyrosine was also noted in the present investigation, as shown by the data in table 5. It is of interest to note that the decrease in tyrosine content was accompanied by a corresponding decrease in tensile strength, and that treatments which tended to increase the stability of the silk decreased the amount of tyrosine destroyed.

TABLE 5.-Photochemical decomposition of treated and untreated silk measured by change in tyrosine content and breaking strength



\section{PRACTICAL SIGNIFICANCE}

The above observations show that the stability of silk to light can be considerably increased by treatment with suitable cationic reagents. Experiments with several organic bases show that the undesirable effects produced by inorganic bases can be avoided by the use of proper organic reagents. In addition, the latter type of compounds appears to be more efficient in regard to stabilizing the silk. It should be noted that, with the exception of the diazomethane treatment, none of the effects of the treatments used in this work was of a permanent nature, since the stabilizing effect was removed by washing the fabrics with water. It may be possible to develop colorless, basic compounds which might have sufficiently high affinities for the fiber so that they would resist removal by washing in neutral or alkaline solutions. Whether any of these treatments will affect 
other properties of the fabric, such as light-fastness of the dye which may be used, can only be determined for the materials to which such reagents may be applied.

\section{REFERENCES}

[1] Harris and Jessup, BS J. Research 7,1179 (1931) RP395.

[2] Harris, J. Research NBS 13, 151 (1934) RP697.

[3] Hall, Textile Colorist 59, 39 (1937).

[4] Bonicatti, Boll. ufficiale staz. sper. seta. \%, 90 (1937).

[5] Weilenmann, Bull. fédération intern. assoc. chim. textile couleur 3, 157 (1938).

[6] Gleysteen and Harris, J. Research NBS 26, 71 (1941) RP1360; Am. Dyestuff Rptr. 30, 25 (1941); Text. Research 11, 117 (1941).

[7] Rutherford, Patterson and Harris, J. Research NBS 25, 451 (1940) RP1338; Textile Research 11, 15 (1940); Am. Dyestuff Rptr. 29, 583 (1940).

[8] Sookne, Fugitt, and Steinhardt, J. Research NBS 25, 61 (1940) RP1314; Textile Research 10, 380 (1940); Am. Dyestuff Rptr. 29, 333 (1940).

[9] Lugg, Biochem. J. 31, 1422 (1937); 32, 775 (1938).

[10] Vieböck and Brecher, Ber. deut. chem. Ges. 63B, 3207 (1930).

[11] Morton and Stubbs, J. Chem. Soc. 1940, 1347.

[12] Arnow, J. Biol. Chem. 110, 43 (1935); 120, 150 (1937).

[13] Berhart and Arnow, J. Phys. Chem. 43, 733 (1939).

[14] Mitchell and Rideal, Proc. Roy. Soc. (London) A167, 342 (1938).

Washington, March 26, 1941. 